\title{
Impact of Physical Fitness on Cognitive Performance in Patients at a Memory Clinic
}

\author{
Katharina Gnosa Agnies Marczak Jana Binder Georg Adler \\ Institut für Studien zur Psychischen Gesundheit (ISPG), Mannheim, Germany
}

\section{Keywords}

Physical fitness · Motor fitness · Cardiorespiratory fitness · Cognitive performance ·

Alzheimer's dementia

\section{Abstract}

Objective: To examine the impact of cardiovascular and motor fitness on cognitive performance in subjects interested in the prevention and early recognition of Alzheimer's dementia (AD). Methods: The data of 388 participants of a respective project aged between 50 and 85 years were evaluated. Classification of the participants into the groups of "no cognitive impairment" $(\mathrm{NCl})$, "mild cognitive impairment of the amnestic type" (MCla), and "mild AD" (mAD) was performed by neuropsychological assessment, history of third party, and further clinical, laboratory, or imaging investigations. Subjective memory impairment (SMI) and cognitive blackouts were recorded. Cardiorespiratory fitness (CRF) was assessed by means of the 2-min step test and motor fitness (MF) by means of the 30-s chair-stand test. Results: CRF and MF were reduced in participants with MCla and MAD. They were negatively correlated with the score for cognitive blackouts. In the group of 50- to 60-year-old nondemented participants those with low CRF and MF performed poorer in various cognitive domains, had a higher score for cognitive blackouts, and more frequently SMI. Conclusion: Low CRF and MF are associated with cognitive impairment. This applies even in 50- to 60-year-old nondemented subjects without marked physical morbidity. These findings support the potential usefulness of physical exercise for dementia prevention. 


\section{Introduction}

Low cardiorespiratory fitness may be a risk factor for cognitive decline $[1,2]$. Thus, we examined the impact of physical fitness on cognitive performance in participants of a project for the prevention and early recognition of Alzheimer's dementia (AD).

Physical fitness is a set of attributes that are either health- or skill-related. In contrast to physical fitness, physical activity is defined as bodily movement produced by skeletal muscles resulting in energy expenditure and physical exercise as purposive physical activity in order to improve or maintain physical fitness [3]. Two components of physical fitness can be distinguished: (1) "cardiorespiratory fitness" (CRF), mainly reflecting the level of metabolic and energetic processes; and (2) "motor fitness" (MF), mainly reflecting the level of perceptive and coordinative skills. Both, $\mathrm{CRF}$ and MF have been shown to be differentially related to cognitive performance $[4,5]$; however, the literature on CRF is clearly prevailing.

The gold standard for the measurement of CRF is the maximum oxygen uptake when performing physical activity [6]. In epidemiologic studies, endurance tests are usually applied instead [7]. In older adults, CRF is positively related to cognitive function and may reduce the risk of developing dementia [8]. A low CRF has been found to be correlated with hippocampal volume loss [9], with cognitive impairment [10-12], and to predict cognitive decline [13, 14].

In order to assess the impact of physical fitness on cognitive performance in older adults, we examined CRF and MF in the participants of a project for the prevention and early recognition of $\mathrm{AD}$ and related the findings to cognitive performance and the self-perception of cognitive impairment. As an early sign of incipient AD, we assessed self-perceived cognitive blackouts by means of a recently developed rating instrument, the Checklist for Cognitive Blackouts (CCB) [15].

\section{Methods}

This retrospective analysis was carried out in data collected at a project for the prevention and early recognition of $A D$ at Mannheim. Within this project (Kogifit ${ }^{\circledR}$ Plus), which is conducted since 2015, cognitive performance, subjective memory impairment (SMI), selfperceived cognitive blackouts, and various risk factors for the development of AD are assessed.

Demographic data, medication, and medical history with particular reference to head trauma, diabetes mellitus, arterial hypertension, and hypercholesterolemia were taken in a standardized manner.

Assessment of cognitive performance and assignment to the diagnostic groups of "no cognitive impairment" (NCI), "mild cognitive impairment of the amnestic type" (MCIa), and "mild AD" (mAD) were performed by means of the Structured Interview for the Diagnosis of dementia of the Alzheimer type, Multi-infarct dementia and dementias of other etiology according to ICD-10 and DSM-III-R (SIDAM) [16]. The neuropsychological test battery of the SIDAM includes the Mini-Mental State Examination (MMSE) [17]. If appropriate, further clinical, laboratory, or imaging investigations were initiated. Depressive symptoms were examined by means of the German version of the Beck Depression Inventory (BDI-II) [18].

The presence of SMI was analyzed by asking the patients: (1) Do you feel like your memory is becoming worse? (2) If so, does it worry you? (3) Do you think that your memory is poorer than that of other persons of your age? Self-perceived cognitive blackouts were assessed by means of the CCB [15].

The physical examination included the assessment of body mass index (BMI) and waist circumference. Physical fitness was assessed by means of two subtests of the Senior Fitness Test $[19,20]$ : (1) The Step Test (ST), which mainly reflects cardiovascular fitness. The partic- 
ipants were asked to repeatedly raise each knee to a point midway between patella and iliac crest as frequently as possible for $2 \mathrm{~min}$. The number of full steps (not just right steps, as in the original instruction for the test) completed was recorded; and (2) The Chair Stand Test (CST), which mainly reflects MF. The participants were asked to repeatedly stand up from and sit down on a chair for $30 \mathrm{~s}$ as fast as possible. The number of stands was recorded. Cutoffs for low physical fitness measured by means of ST and CST had been determined previously in a large group of 50- to 85-year-old subjects as 25-percent rank values.

Demographic variables, medical history, body size, and physical fitness for the participant groups with NCI, MCIa, and mAD were compared by means of one-way ANOVAs for the continuous variables and by means of $\chi^{2}$ tests for the categorical variables. The relationships of physical fitness to cognitive performance and cognitive blackouts were examined by means of Pearson's partial correlation coefficients (corrected for age). In order to control for the effects of age and physical morbidity, cognitive performance and self-perceived memory impairment were compared in the 50- to 60-year-old nondemented participants for the ones with impaired and unimpaired CRF and MF by means of one-way ANOVAs and $\chi^{2}$ tests.

\section{Results}

In the period between April 2015 and March 2018 Kogifit ${ }^{\circledR}$ Plus assessments were carried out in 436 participants. In 48 of them, comorbidities relevant for cognitive performance were found, most frequently depressive disorders with a BDI score of more than $20(n=14)$, cerebrovascular disorders $(n=13)$, and harmful alcohol consumption of more than $40 \mathrm{~g}$ per day for men and more than $20 \mathrm{~g}$ per day for women $(n=10)$. These participants were excluded from the subsequent analyses.

In the remaining 388 participants, diagnoses on cognitive status were made based on subjective complaints, neuropsychological testing, as well as medical history from third party, laboratory examinations, and cerebral imaging (in subjects with possible AD). We found 195 participants $(50.3 \%)$ with NCI, 129 participants (33.2\%) with MCIa, and 64 participants $(16.5 \%)$ with $\mathrm{mAD}$. Physical fitness could not be assessed in 64 participants $(16.5 \%)$ for the ST and in 35 participants (9.0\%) for the CST, most frequently because of orthopedic hip or knee problems. Demographic and clinical data of the study groups are given in Table 1.

Compared to the participants with NCI, participants with MCIa und mAD were older, had less years of education, and were less frequently female. The latter difference may be a selection artifact, as women tend to use preventive examinations more frequently than men and thus may prevail most strongly in the group without objective impairment.

A history of diabetes mellitus and arterial hypertension was more frequent in the MCIa and mAD participants. There were no differences in BMI and waist circumference between the study groups. However, $\mathrm{CRF}$ and MF were reduced in participants with MCIa and MAD.

Examining the relationships of physical fitness to cognitive performance and cognitive blackouts by calculating Pearson's partial correlation coefficients (corrected for age), we found significant negative correlations between the CCB score and ST ( $r=-0.172 ; p=0.025)$ as well as CST ( $\mathrm{r}=-0.167 ; p=0.030$ ). Examining these relationships in detail, we found that appropriate cutoffs for both types of fitness clearly separated participants with and without increased scores for cognitive blackouts. For the CST, these cutoffs were "less or equal 15" versus "more than 15" stand-ups, for the ST "less or equal 100" versus "more than 100" steps. The respective values of the CCB score for the CST categories were $6.1 \pm 2.6$ versus $5.1 \pm 1.8(\mathrm{~T}=3.134 ; p=$ $0.002)$ and for the ST categories, they were $6.0 \pm 2.4$ versus $5.2 \pm 2.0(\mathrm{~T}=2.554 ; p=0.012)$.

In order to rule out age-associated morbidity and frailty as a common cause for both physical and cognitive impairment, we studied the relationship of physical fitness to cognitive 
Table 1. Demographic and clinical data of the study groups

\begin{tabular}{|c|c|c|c|c|c|}
\hline Demographic and clinical variables & $\mathrm{NCI}(n=195)$ & MCIa $(n=129)$ & $\mathrm{mAD}(n=64)$ & $\mathrm{F} / \chi^{2}$ & $p$ \\
\hline Age, years & $61.2 \pm 8.0$ & $66.5 \pm 8.8$ & $75.2 \pm 7.4$ & $F=73.4$ & $<0.001$ \\
\hline Years of education & $14.7 \pm 3.1$ & $13.5 \pm 2.5$ & $11.9 \pm 3.6$ & $\mathrm{~F}=12.4$ & $<0.001$ \\
\hline Female gender & $132 / 195(68 \%)$ & $75 / 129(58 \%)$ & $33 / 64(52 \%)$ & $\chi^{2}=6.44$ & $<0.040$ \\
\hline \multicolumn{6}{|l|}{ Medical history } \\
\hline Head trauma & $25 / 195(13 \%)$ & $21 / 129(16 \%)$ & $9 / 64(14 \%)$ & $\chi^{2}=0.76$ & ns \\
\hline Diabetes mellitus & $13 / 195(7 \%)$ & $20 / 129(16 \%)$ & $9 / 64(14 \%)$ & $\chi^{2}=7.11$ & 0.029 \\
\hline Arterial hypertension & $66 / 195(34 \%)$ & $61 / 129(47 \%)$ & $42 / 64(66 \%)$ & $\chi^{2}=20.89$ & $<0.001$ \\
\hline Hypercholesterolemia & $65 / 130(33 \%)$ & $59 / 129(46 \%)$ & $28 / 64(44 \%)$ & $\chi^{2}=5.69$ & ns \\
\hline \multicolumn{6}{|l|}{ Body size } \\
\hline BMI, $\mathrm{kg} / \mathrm{m}^{2}$ & $27.2 \pm 5.2$ & $27.2 \pm 5.7$ & $25.8 \pm 4.2$ & $F=2.0$ & ns \\
\hline Waist circumference, $\mathrm{cm}$ & $102 \pm 15$ & $102 \pm 14$ & $103 \pm 12$ & $\mathrm{~F}=0.1$ & ns \\
\hline \multicolumn{6}{|l|}{ Physical fitness } \\
\hline ST $(n=324)$ & $114 \pm 33$ & $108 \pm 35$ & $98 \pm 37$ & $F=4.1$ & 0.018 \\
\hline $\operatorname{CST}(n=353)$ & $17 \pm 5$ & $16 \pm 5$ & $13 \pm 4$ & $\mathrm{~F}=13.9$ & $<0.001$ \\
\hline
\end{tabular}

Data on demography, medical history, and physical examination are given for the study groups of subjects with NCI, with MCIa, and with mAD. Cardiorespiratory fitness was assessed by means of the ST and motor fitness by means of the CST. Significances of group differences were calculated by one-way ANOVAs for the continuous variables and by $\chi^{2}$ tests for the dichotomous categorical variables (sex and medical history). NCI, no cognitive impairment; MCIa, mild cognitive impairment of the amnestic type; mAD, mild Alzheimer's dementia; ST, Step Test; CST, Chair Stand Test.

performance, subjective cognitive impairment, and cognitive blackouts in the 50- to 60-year-old participants who were not suffering from AD. This group is made up of 135 participants, in 128 (94.8\%) of whom the CST and in 125 (92.6\%) the ST could be performed. We examined, whether there were differences in cognitive performance, SMI, and cognitive blackouts for participants below and above the cutoffs for both tests. The relationships of CRF (ST) and MF (CST) to cognitive performance, SMI, and cognitive blackouts are given in Table 2.

CRF was higher in female participants and those without a history of arterial hypertension. The participants with higher CRF had a higher score in orientation and a higher MMSE score. They also had less frequently cognitive blackouts and were more rarely concerned about having a poor memory. MF was not related to age, years of education, sex, or medical history, but the participants with a higher MF had a lower BMI and a lower waist circumference. With respect to cognitive performance, the participants with a higher MF had higher scores in orientation, speech, and praxis as well as higher cortical functions. They also had less frequently cognitive blackouts and were complaining more rarely about SMI.

\section{Discussion}

Our findings on the relationship between CRF and cognitive performance in older adults are in good agreement with the frequently reported positive correlation between CRF and cognitive performance [10-12]. It also has been shown in longitudinal studies that a good CRF predicts a good preservation of cognitive performance $[13,14]$. The findings on the positive correlations of MF with cognition are in line with the findings of Voelcker-Rehage et al. $[4,5]$.

When comparing the relationships of CRF (as assessed by the ST) and MF (as assessed by the CST) to cognition, it appears that CRF is related tighter to physical health, indicated by a higher percentage of women and a lower prevalence of arterial hypertension in the participants with good CRF. Participants with good CRF had a higher orientation score, a higher 
Table 2. Physical fitness, cognitive performance, subjective memory impairments, and cognitive blackouts in 50- to 60-year-old nondemented subjects

\begin{tabular}{|c|c|c|c|c|c|c|c|c|}
\hline \multirow[t]{2}{*}{ Participant variables } & \multicolumn{2}{|l|}{ ST } & \multirow[t]{2}{*}{$\mathrm{T} / \chi^{2}$} & \multirow[t]{2}{*}{$p$} & \multicolumn{2}{|l|}{ CST } & \multirow[t]{2}{*}{$\mathrm{T} / \chi^{2}$} & \multirow[t]{2}{*}{$p$} \\
\hline & $\begin{array}{l}\leq 100 \\
(n=35)\end{array}$ & $\begin{array}{l}>100 \\
(n=88)\end{array}$ & & & $\begin{array}{l}\leq 15 \\
(n=39)\end{array}$ & $\begin{array}{l}>15 \\
(n=87)\end{array}$ & & \\
\hline \multicolumn{9}{|l|}{ Demographic data } \\
\hline Age, years & $55.5 \pm 2.8$ & $55.0 \pm 3.0$ & $\mathrm{~T}=0.955$ & ns & $55.3 \pm 2.8$ & $55.2 \pm 3.0$ & $\mathrm{~T}=0.276$ & ns \\
\hline Years of education & $14.7 \pm 2.7$ & $14.7 \pm 2.6$ & $\mathrm{~T}=0.027$ & ns & $14.5 \pm 2.8$ & $14.7 \pm 2.6$ & $\mathrm{~T}=-1.13$ & ns \\
\hline Female gender & $\begin{array}{l}20 / 35 \\
(57 \%)\end{array}$ & $\begin{array}{l}66 / 88 \\
(75 \%)\end{array}$ & $\chi^{2}=3.796$ & 0.043 & $\begin{array}{l}28 / 39 \\
(72 \%)\end{array}$ & $\begin{array}{l}61 / 87 \\
(70 \%)\end{array}$ & $\chi^{2}=0.037$ & ns \\
\hline \multicolumn{9}{|l|}{ Medical history } \\
\hline Head trauma & $\begin{array}{l}4 / 35 \\
(11 \%)\end{array}$ & $\begin{array}{l}10 / 35 \\
(11 \%)\end{array}$ & $\chi^{2}=0.000$ & ns & $\begin{array}{l}7 / 39 \\
(18 \%)\end{array}$ & $\begin{array}{l}7 / 87 \\
(8 \%)\end{array}$ & $\chi^{2}=2.674$ & ns \\
\hline Diabetes mellitus & $\begin{array}{l}2 / 35 \\
(6 \%)\end{array}$ & $\begin{array}{l}6 / 88 \\
(7 \%)\end{array}$ & $\chi^{2}=0.050$ & ns & $\begin{array}{l}4 / 39 \\
(10 \%)\end{array}$ & $\begin{array}{l}5 / 87 \\
(6 \%)\end{array}$ & $\chi^{2}=0.826$ & ns \\
\hline Arterial hypertension & $\begin{array}{l}12 / 35 \\
(34 \%)\end{array}$ & $\begin{array}{l}15 / 88 \\
(17 \%)\end{array}$ & $\chi^{2}=4.344$ & 0.035 & $\begin{array}{l}12 / 39 \\
(31 \%)\end{array}$ & $\begin{array}{l}16 / 87 \\
(18 \%)\end{array}$ & $\chi^{2}=2.387$ & ns \\
\hline Hypercholesterolemia & $\begin{array}{l}13 / 35 \\
(7 \%)\end{array}$ & $\begin{array}{l}24 / 88 \\
(27 \%)\end{array}$ & $\chi^{2}=1.160$ & ns & $\begin{array}{l}12 / 39 \\
(31 \%)\end{array}$ & $\begin{array}{l}26 / 87 \\
(30 \%)\end{array}$ & $\chi^{2}=0.010$ & ns \\
\hline \multicolumn{9}{|l|}{ Body size } \\
\hline BMI, $\mathrm{kg} / \mathrm{m}^{2}$ & $26.7 \pm 5.2$ & $26.6 \pm 5.6$ & $\mathrm{~T}=0.132$ & ns & $27.8+5.3$ & $26.6+6.4$ & $\mathrm{~T}=2.034$ & 0.043 \\
\hline Waist circumference, $\mathrm{cm}$ & $102 \pm 12$ & $97 \pm 16$ & $\mathrm{~T}=1.767$ & ns & $103 \pm 11$ & $96 \pm 17$ & $\mathrm{~T}=4.347$ & $<0.001$ \\
\hline \multicolumn{9}{|l|}{ Cognitive performance } \\
\hline Orientation & $9.5 \pm 0.7$ & $9.8 \pm 0.4$ & $\mathrm{~T}=-2.635$ & 0.010 & $9.6 \pm 0.7$ & $9.8 \pm 0.4$ & $\mathrm{~T}=-2.485$ & 0.014 \\
\hline Recall & $4.6 \pm 0.7$ & $4.8 \pm 0.5$ & $\mathrm{~T}=-1.685$ & ns & $4.6 \pm 0.6$ & $4.8 \pm 0.5$ & $\mathrm{~T}=-1.696$ & ns \\
\hline Short-term memory & $6.9 \pm 1.4$ & $7.1 \pm 1.0$ & $\mathrm{~T}=-0.969$ & ns & $6.9 \pm 1.4$ & $7.2 \pm 1.0$ & $\mathrm{~T}=-1.425$ & ns \\
\hline Long-term memory & $5.8 \pm 1.1$ & $5.9 \pm 1.0$ & $\mathrm{~T}=-0.549$ & ns & $5.8 \pm 1.1$ & $5.9 \pm 1.0$ & $\mathrm{~T}=-0.206$ & ns \\
\hline Memory & $17.3 \pm 2.3$ & $17.8 \pm 1.8$ & $\mathrm{~T}=-1.301$ & ns & $17.3 \pm 2.3$ & $17.8 \pm 1.8$ & $\mathrm{~T}=-1.501$ & ns \\
\hline Intellectual cap. & $4.7 \pm 0.7$ & $4.8 \pm 0.5$ & $\mathrm{~T}=-0.657$ & ns & $4.7 \pm 0.7$ & $4.8 \pm 0.5$ & $\mathrm{~T}=-0.658$ & ns \\
\hline Verbal/calc. cap. & $6.0 \pm 1.6$ & $6.2 \pm 1.1$ & $\mathrm{~T}=-0.810$ & ns & $5.9 \pm 1.5$ & $6.3 \pm 1.0$ & $\mathrm{~T}=-1.519$ & ns \\
\hline Visuospatial cap. & $2.6 \pm 0.8$ & $2.7 \pm 0.7$ & $\mathrm{~T}=-0.134$ & ns & $2.6 \pm 0.8$ & $2.7 \pm 0.7$ & $\mathrm{~T}=-0.561$ & ns \\
\hline Aphasia/apraxia & $9.5 \pm 1.1$ & $9.6 \pm 0.6$ & $\mathrm{~T}=-0.762$ & ns & $9.4 \pm 1.1$ & $9.8 \pm 0.4$ & $\mathrm{~T}=-2.547$ & 0.012 \\
\hline Higher cort. funct. & $18.2 \pm 2.6$ & $18.6 \pm 1.5$ & $\mathrm{~T}=-0.920$ & ns & $17.9 \pm 2.5$ & $18.7 \pm 1.4$ & $\mathrm{~T}=-2.283$ & 0.024 \\
\hline MMSE score & $28.3 \pm 2.3$ & $28.9 \pm 1.1$ & $\mathrm{~T}=-2.020$ & 0.046 & $28.3 \pm 2.1$ & $28.9 \pm 1.1$ & $\mathrm{~T}=-1.896$ & ns \\
\hline \multicolumn{9}{|c|}{ Self-perceived memory impairment } \\
\hline Blackouts (CCB) & $6.3 \pm 2.4$ & $5.1 \pm 1.9$ & $\mathrm{~T}=2.203$ & 0.030 & $6.1 \pm 2.5$ & $5.1 \pm 1.8$ & $\mathrm{~T}=2.003$ & 0.048 \\
\hline SMI ("impairment") & $\begin{array}{l}26 / 35 \\
(74 \%)\end{array}$ & $\begin{array}{l}58 / 88 \\
(66 \%)\end{array}$ & $\chi^{2}=0.811$ & ns & $\begin{array}{l}33 / 39 \\
(85 \%)\end{array}$ & $\begin{array}{l}54 / 87 \\
(62 \%)\end{array}$ & $\chi^{2}=6.405$ & 0.008 \\
\hline SMI ("concern") & $\begin{array}{l}26 / 35 \\
(74 \%)\end{array}$ & $\begin{array}{l}38 / 88 \\
(43 \%)\end{array}$ & $\chi^{2}=9.706$ & 0.002 & $\begin{array}{l}25 / 39 \\
(64 \%)\end{array}$ & $\begin{array}{l}42 / 87 \\
(48 \%)\end{array}$ & $\chi^{2}=2.709$ & ns \\
\hline SMI (“comparison") & $\begin{array}{l}14 / 35 \\
(40 \%)\end{array}$ & $\begin{array}{l}30 / 88 \\
(34 \%)\end{array}$ & $\chi^{2}=0.381$ & ns & $\begin{array}{l}17 / 39 \\
(44 \%)\end{array}$ & $\begin{array}{l}28 / 87 \\
(32 \%)\end{array}$ & $\chi^{2}=1.526$ & ns \\
\hline
\end{tabular}

The differences in demographic variables, medical history, body size, cognitive performance, and self-perceived cognitive impairment for subjects with low and high cardiorespiratory fitness (ST $\leq 100 \mathrm{vs.} \mathrm{ST}>100$ ) and for subjects with low and high motor fitness (CST $\leq 15$ vs. CST $>15$ ) were calculated by unpaired Student's $t$ tests for the continuous variables and by $\chi^{2}$ tests for the dichotomous categorical variables. Under "cognitive performance" the values for the SIDAM syndromes are given. ST, Step Test; CST, Chair Stand Test; BMI, body mass index; intellectual cap., intellectual capabilities; verbal/calc. cap., verbal and calculation capabilities; visuospatial cap., visuospatial capabilities; higher cort. funct., higher cortical functions; MMSE, Mini-Mental State Examination; CCB, Checklist for Cognitive Blackouts; SMI, subjective memory impairment. 
MMSE global score, reported less frequently cognitive blackouts and were less frequently concerned about their memory. In contrast, MF had no significant relationships to physical health, but participants with a good MF had a lower BMI and a smaller waist circumference. With respect to objective and subjective cognitive impairment, a good MF was related to less impairment in orientation, speech, practical capabilities, and higher cortical functions. Participants with a good MF reported less frequently cognitive blackouts and memory impairment. It appears as if MF is a more subtle dimension compared to CRF, with a weaker correlation with physical health and a stronger correlation with physical and mental agility.

Various mechanisms may account for the correlations between physical fitness and cognitive performance in older adults. CRF has been found to be positively correlated with cerebral white matter integrity $[21,22]$ and with gray matter volume in the prefrontal cortex and the hippocampus [23]. These correlations may be mediated by metabolic mechanisms [24].

Functional MRI studies show that the default mode network is sensitive to age-related decline and tightly related to CRF [25]. Functional connectivity within the default mode network, which is also reflected by resting EEG coherence is correlated with cognitive performance [26]. It has also been shown that high CRF reduces the effects of beta-amyloid depositions on learning and memory [27] and attenuates the adverse influence of genetic vulnerability on CSF biomarkers [28].

There are two major limitations of this study. The first limitation is the cross-sectional design in an unselected population of users of a memory prevention program. This design may produce selection artifacts, e.g. probably the larger proportion of women compared to men in the less impaired participant groups. The second limitation results from the comparatively unelaborated assessments for cognition as well as for physical fitness, as they are applied in a memory clinic's routine setting. It must be assumed that ST and CST do not clearly differentiate between CRF and MF as both tasks require a certain minimum of cardiorespiratory and motor capabilities. On the other hand, it may be reasonable to assume that impaired $\mathrm{CRF}$ is the major limiting factor for the ST as is impaired MF for the CST.

We could ascertain the correlation between poor physical fitness and impaired cognitive performance applying comparatively simple methods in a routine memory clinic setting and in 50- to 60-year-old nondemented subjects without marked physical morbidity. These findings support the potential usefulness of physical exercise for dementia prevention.

\section{Acknowledgment}

The study was sponsored in part by a research grant of the Karin Nolte Foundation Germersheim, Germany.

\section{Statement of Ethics}

This study was approved by the Mannheim Medical Faculty Ethics Committee.

\section{Disclosure Statement}

There are no conflicts of interest to disclose. 


\section{References}

1 Albert MS, Jones K, Savage CR, Berkman L, Seeman T, Blazer D, et al. Predictors of cognitive change in older persons: MacArthur studies of successful aging. Psychol Aging. 1995 Dec;10(4):578-89.

2 Yaffe K, Barnes D, Nevitt M, Lui LY, Covinsky K. A prospective study of physical activity and cognitive decline in elderly women: women who walk. Arch Intern Med. 2001 Jul;161(14):1703-8.

3 Caspersen CJ, Powell KE, Christenson GM. Physical activity, exercise, and physical fitness: definitions and distinctions for health-related research. Public Health Rep. 1985 Mar-Apr;100(2):126-31.

4 Voelcker-Rehage C, Godde B, Staudinger UM. Physical and motor fitness are both related to cognition in old age. Eur J Neurosci. 2010 Jan;31(1):167-76.

5 Voelcker-Rehage C, Godde B, Staudinger UM. Cardiovascular and coordination training differentially improve cognitive performance and neural processing in older adults. Front Hum Neurosci. 2011 Mar; 5:26.

6 Taylor HL, Buskirk E, Henschel A. Maximal oxygen intake as an objective measure of cardio-respiratory performance. J Appl Physiol. 1955 Jul;8(1):73-80.

7 Jetté M. The standardized test of fitness in occupational health: a pilot project. Can J Public Health. 1978 Nov-Dec;69(6):431-8.

8 Erickson KI, Weinstein AM, Lopez OL. Physical activity, brain plasticity, and Alzheimer's disease. Arch Med Res. 2012 Nov; 43(8):615-21.

9 Erickson KI, Prakash RS, Voss MW, Chaddock L, Hu L, Morris KS, et al. Aerobic fitness is associated with hippocampal volume in elderly humans. Hippocampus. 2009 Oct;19(10):1030-9.

10 Colcombe S, Kramer AF. Fitness effects on the cognitive function of older adults: a meta-analytic study. Psychol Sci. 2003 Mar;14(2):125-30.

11 Netz Y, Dwolatzky T, Zinker Y, Argov E, Agmon R. Aerobic fitness and multidomain cognitive function in advanced age. Int Psychogeriatr. 2011 Feb;23(1):114-24.

12 Bullock AM, Mizzi AL, Kovacevic A, Heisz JJ. The association of aging and aerobic fitness with memory. Front Aging Neurosci. 2018 Mar; 10:63.

13 Barnes DE, Yaffe K, Satariano WA, Tager IB. A longitudinal study of cardiorespiratory fitness and cognitive function in healthy older adults. J Am Geriatr Soc. 2003 Apr;51(4):459-65.

14 Wendell CR, Gunstad J, Waldstein SR, Wright JG, Ferrucci L, Zonderman AB. Cardiorespiratory fitness and accelerated cognitive decline with aging. J Gerontol A Biol Sci Med Sci. 2014 Apr;69(4):455-62.

15 Adler G, Marczak A, Binder J. Cognitive blackouts in mild cognitive impairment and Alzheimer's dementia. Dement Geriatr Cogn Disord Extra. 2018 Feb;8(1):72-6.

16 Zaudig M, Hiller W. SIDAM - Strukturiertes Interview für die Diagnose einer Demenz vom Alzheimer Typ, der Multiinfarkt- (oder vaskulären) Demenz und Demenzen anderer Ätiologie nach DSM-III-R, DSM-IV und ICD-10 (SIDAM-Handbuch). Bern: Huber; 1996.

17 Folstein MF, Folstein SE, McHugh PR. "Mini-mental state". A practical method for grading the cognitive state of patients for the clinician. J Psychiatr Res. 1975 Nov;12(3):189-98.

18 Hautzinger M, Keller F, Kühner C. Beck Depressions-Inventar (BDI-II). Revision. Frankfurt/Main: Harcourt Test Services; 2006.

19 Rikli RE, Jones CJ. Development and validation of a functional fitness test for community-residing older adults. J Aging Phys Act. 1999;7(2):129-61.

20 Rikli RE, Jones CJ. Senior fitness test manual. Champaign: Human Kinetic; 2001.

21 Johnson NF, Kim C, Clasey JL, Bailey A, Gold BT. Cardiorespiratory fitness is positively correlated with cerebral white matter integrity in healthy seniors. Neuroimage. 2012 Jan;59(2):1514-23.

22 Voss MW, Heo S, Prakash RS, Erickson KI, Alves H, Chaddock L, et al. The influence of aerobic fitness on cerebral white matter integrity and cognitive function in older adults: results of a one-year exercise intervention. Hum Brain Mapp. 2013 Nov;34(11):2972-85.

23 Erickson KI, Leckie RL, Weinstein AM. Physical activity, fitness, and gray matter volume. Neurobiol Aging. 2014 Sep;35 Suppl 2:S20-8.

24 Cotman CW, Berchtold NC, Christie LA. Exercise builds brain health: key roles of growth factor cascades and inflammation. Trends Neurosci. 2007 Sep;30(9):464-72.

25 Voss MW, Erickson KI, Prakash RS, Chaddock L, Malkowski E, Alves H, et al. Functional connectivity: a source of variance in the association between cardiorespiratory fitness and cognition? Neuropsychologia. 2010 Apr; 48(5):1394-406.

26 Adler G, Brassen S, Jajcevic A. EEG coherence in Alzheimer's dementia. J Neural Transm (Vienna). 2003 Sep; 110(9):1051-8.

27 Schultz SA, Boots EA, Almeida RP, Oh JM, Einerson J, Korcarz CE, et al. Cardiorespiratory fitness attenuates the influence of amyloid on cognition. J Int Neuropsychol Soc. 2015 Nov;21(10):841-50.

28 Schultz SA, Boots EA, Darst BF, Zetterberg H, Blennow K, Edwards DF, et al. Cardiorespiratory fitness alters the influence of a polygenic risk score on biomarkers of AD. Neurology. 2017 Apr;88(17):1650-8. 